\title{
Darwin's geology
}

\author{
The Charles Darwin bicentennial celebrates the man who recognized natural selection and changed the \\ world's views on evolution. However, his contributions to geology should not be overlooked.
}

12 February marks the 200th anniversary of the birth of Charles Darwin. As the world prepares to celebrate Darwin Day and the 150th anniversary of the publication of On the Origin of Species in October, attention is - quite

rightly - focused on Darwin's contributions to our understanding of evolution and life on Earth. However, given the focus of Nature Geoscience, we would like to note that Darwin also contributed to our understanding of geology.

Darwin, like many intellectuals of his era, was well versed in a variety of natural sciences, as well as in medicine and theology. When he set forth on his first voyage aboard the HMS Beagle, he was armed with Charles Lyell's contentious book Principles of Geology, as well as his specimen collecting equipment (S. Herbert, Charles Darwin, Geologist, Cornell Univ. Press; 2005). The Beagle's voyage took him to landscapes that naturally posed geological questions. In one instance, he encountered a band of rocks, high in the cliffs of Santiago, Cape Verde, that was well above sea level, yet full of marine fossils. As the journey continued, Darwin's accumulating observations led him to support Lyell's theory that the Earth's surface was shaped largely by the gradual changes that were observed occurring at present, a principle that later became known as uniformitarianism. At the time, this was in stark contrast to geological theory that called for sudden, catastrophic events, unlike any ever witnessed, able to immediately flood oceans or raise mountains.

Darwin's letters to his mentor John Stevens Henslow, a professor of botany at Cambridge University, were later read to the Cambridge Philosophical Society, and described his observations of ongoing uplift in the Andes, as well as interpretations of tilting and igneous activity. Darwin took extensive notes on the active geology of South America and went on to publish three books on the subject (all of which preceded his publications on evolution). This early geological work already showed Darwin as an independent thinker unimpressed by majority opinion, a quality much needed for his later, much more provocative publications on evolution.

The lush fauna and the shapes and formations of coral reefs held a particular fascination for Darwin. One of his earliest publications was entitled The Structure and Distribution of Coral Reefs (Smith Elder; 1842). The manuscript describes the coral atolls he encountered throughout the Pacific Ocean. Atolls are shallow lagoons surrounded by large coral reefs that seem to rise from the deep ocean. Prevailing theory at the time held that the atolls were formed as corals took root and grew on undersea craters. Yet in all his travels, Darwin never encountered anything that could explain the presence of such large and oddly shaped craters throughout the oceans.

Instead, Darwin looked to the low-lying islands fringed by coral reefs, such as those in the Maldives. He heard stories from the residents of islands lost through earthquakes and erosion. He proposed that as low-lying islands sink into the sea, coral reefs that fringe the island grow upward, eventually nearing the surface. After some time, the island would be lost, but the reefs remain, continuing to compensate relative sea level rise by their growth. Many of Darwin's geological theories, along with those of his contemporaries, were superseded by plate tectonics. However, his work on coral reefs still stands.

As he travelled the world, collected fossils and observed the fauna and flora around him, Darwin never neglected to note and seek to understand the geology of his destinations. We at Nature Geoscience are pleased to draw some of the attention that is being bestowed on this great man in his double-anniversary year to his interest and achievements in geology.

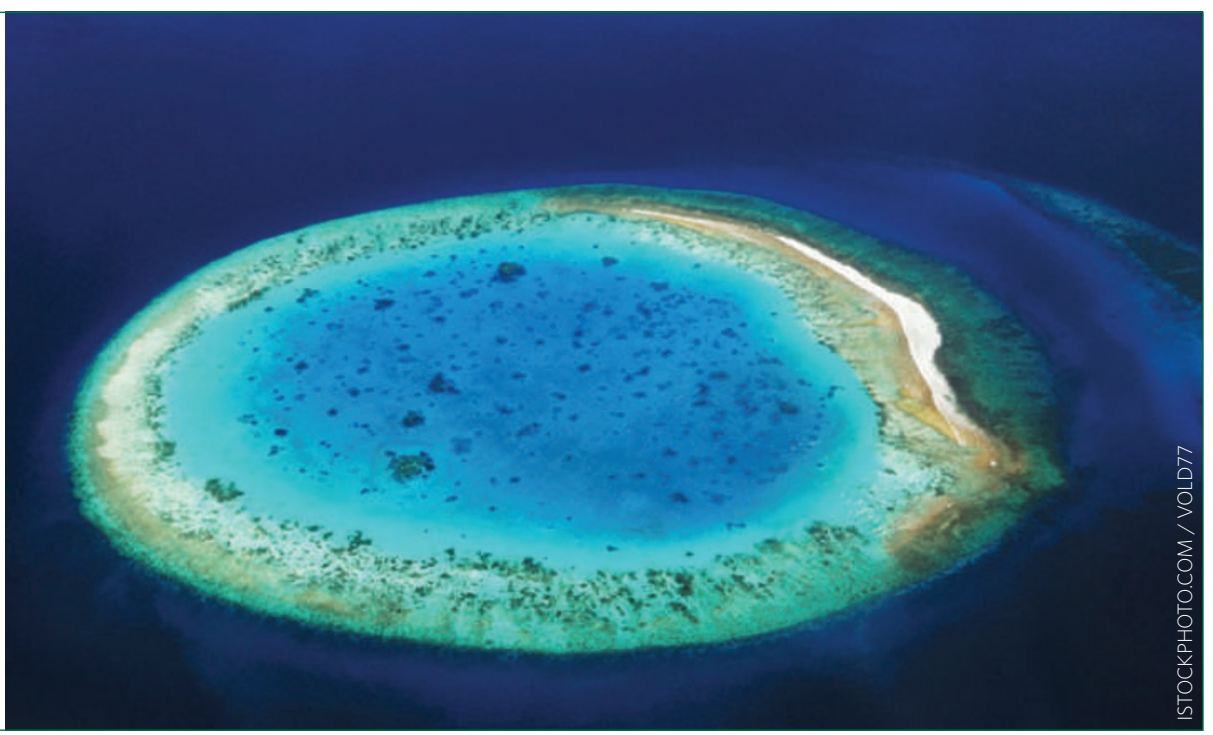

